\title{
Kütük Çapı ve Kütük Yüksekliği ile Göğüs Çapı İlişkisi: Kastamonu- Göynük Örneği
}

\author{
Birsen DURKAYA ${ }^{1 *}$, Cihan DAĞLI ${ }^{1}$ \\ ${ }^{1}$ Bartın Üniversitesi, Orman Fakültesi, Orman Mühendisliği Bölümü,74100, Bartın
}

\section{Öz}

Ormancılık faaliyetleri sırasında usulsüz kesimler önemli orman suçları arasında değerlendirilmektedir. Bu kesimlerle alandan uzaklaştırılmış olan orman ağaçlarının hacimlerinin belirlenmesi gerekmektedir, ancak gögüs yüksekliğindeki çap $\left(\mathrm{d}_{1,30}\right)$ bilinmediği için hesaplamada bazı güçlükler ve hatalar oluşmaktadır. Bu çalışmada çeşitli kütük çapları $\left(\mathrm{d}_{\mathrm{k}}\right)$ ve kütük çapı $\left(\mathrm{d}_{\mathrm{k}}\right)$ ve kütü boyları $\left(\mathrm{h}_{\mathrm{k}}\right)$ kullanılarak göğüs yüksekliğindeki çapın $\left(\mathrm{d}_{1,30}\right)$ belirlenmesi amaçlanmıştır. Kastamonu Orman Bölge Müdürlüğü, Bozkurt Orman İşletme Müdürlüğü, Göynük Orman İşletme Şefliği’ndeki kayın (Fagus orientalis Lipsky.) ağaç türü için farklı kütük yüksekliklerinden $(0,10,0,30$ ve $0,60 \mathrm{~m})$ ölçülen çaplardan, gögüs yüksekliği çapının $\left(\mathrm{d}_{1,30}\right)$ tahmini, bunun yanında kütük çapları ve kütük yüksekliklerinden hareketle $\mathrm{d}_{1,30}$ çapının tahmin edilmesi için ölçümler yapılmıştır. Kayın için, tek ve çift girişli regresyon modelleri denenmiştir. Denenen modeller arasından, belirtme katsayısı $\left(\mathrm{R}_{2}\right)$, standart hata $\left(\mathrm{S}_{\mathrm{yx}}\right)$, F, ortalama sapma (OS), mutlak ortalama sapma (OMS|), ortalama mutlak hata $(\mathrm{OMH})$ ve toplam hata $\mathrm{TH}(\%)$ değerlerine göre, en uygun model seçilmiştir. Çalışma sonucunda hem tek girişli hem de çift girişli denklem olarak logaritmik olan denklem uygun model olarak belirlenmiştir. Seçilen bu modellere göre, tek girişli ve çift girişli göğüs çapı tabloları düzenlenmiştir.

Anahtar Kelimeler: Kütük çap1, kütük yüksekliği, göğüs çap1.

\section{Relation of Log Diameter and Log Height to Breast Diameter: The Case of Kastamonu- Göynük}

\begin{abstract}
During forestry activities, illegal cuttings are considered among the important forest crimes. It is necessary to determine the volumes of forest trees that have been removed from the area with these cuts, but since the diameter at breast height is not known, some difficulties and errors occur in the calculation. In this study, it was aimed to determine the diameter at breast height by using various stump diameters and stump diameterstump lengths. Beech trees were measured to estimate their breast-height diameters $\left(\mathrm{d}_{1,30}\right)$ based on stump diameters and stump diameter-stump height in Bozkurt Forest Enterprise, Göynük Management Unit. For each tree species, single (five candidate equations were tested).and duble-entry regression equation(eight candidate equations were tested.) were fitted. Among these regression models, the most suitable model was determinated according to coefficient of determination $\left(\mathrm{R}^{2}\right)$, standard error $\left(\mathrm{S}_{\mathrm{yx}}\right)$ and $\mathrm{F}$ numbers, mean deviation (OS), absolute mean deviation (OMS), mean absolute error (OMH) and total error (TH (\%)). As a result of the study, the logarithmic equation for both single-input and double-entry equations was determined as the appropriate model. Using the models, single entry and double entry tables were constructed.
\end{abstract}

Keywords: Stump diameter, stump height, diameter at breast height.

\footnotetext{
*Sorumlu Yazar (Corresponding Author):

Birsen DURKAYA (Prof. Dr.); Bartın Üniversitesi, Orman Fakültesi, Orman

Mühendisliği Bölümü, Ağdacı Kampüsü, 74100, Bartın-Türkiye. Tel: +90 (378) 223

5173, Fax: +90 (378) 223 5062, E-mail: bdurkaya@bartin.edu.tr

Geliş (Received) : 13.08 .2021

ORCID: 0000-0002-3132-7044 


\section{Giriş}

Sürdürülebilir orman yönetiminin gerçekleştirme koşullarının başında çok iyi bir envanter çalışmasının yapılması gelmektedir. Orman envanterinin en önemli konularından biri ağaçların ve meşcerelerin hacmidir ve hacmi tahmin etmek için birçok yöntem olmasına rağmen, uygulamada kolaylığından dolayı genellikle ağaç hacim tabloları tercih edilmektedir. Hacım tabloları oluşturulurken, ağaç türünün belli yetişme ortamı koşullarında gerçekleştirmiş olduğu hacminin belirlenmesinde gögüs yüksekliği çap1 $\left(\mathrm{d}_{1,30}\right)$ ile ağaç hacmi arasındaki ilişkiden yararlanılmaktadır. Ağaç hacım tabloları; tek girişli hacım tabloları olarak düzenlenebildiği gibi ağaç boyunun dâhil edilmesiyle çift girişli hacım tabloları olarak ta oluşturulabilmektedir. Ülkemizde önemli ağaç türlerimiz için çeşitli araştırmacılar tarafından düzenlenmiş çok çeşitli hacım tabloları mevcuttur. Ağaç türlerine göre hazırlanmış olan tek girişli hacım tablolarının kullanılabilmesi için ilgili ağaç türüne ait gögüs yüksekliğindeki çapın, çift girişli ağaç hacım tablolarının kullanılabilmesi için ise ağacın gögüs çapı yanında ağaç boyunun da bilinmesi gereklidir. Bağımsız değişken olarak göğüs çapı; hacım tablolarının oluşturulmasının yanında, hasılat çalışmaları, büyüme modelleri ve biyokütle modellerinin oluşturulmasında da ağaç boyu ile birlikte ya da tek başına kullanılabilmektedir. Allometrik denklemlerle orman ekosisteminin anlaşılmasında en pratik kaynak olduğu kabul görmektedir (Heiligmann vd., 1984; Johnson-Weigel, 1990; Corral-Rivasvd, 2007; Durkaya vd., 2009; Özçelik vd., 2010; Durkaya vd., 2019). Dolayısıyla orman envanterinde, ölçümünün kolay olması nedeniyle göğüs yüksekliği çapı $\left(\mathrm{d}_{1,30}\right)$, meşcere yapısının ortaya konulmasında sıklıkla kullanılan en önemli değişkendir.

Dikili haldeki ağaç hacmini veren ağaç hacım tabloları, alandan çeşitli yüksekliklerden usulsüz şekilde kesilerek uzaklaştırılan ağaçların ormanda bırakılan kütük çaplarından ağaç hacmine ulaşmayı mümkün kılmamaktadır. Bu nedenle özellikle usulsüz kesimlerden sonra alan üzerinde kalan ağaç kütüğünün boyutları ile ağaç hacminin belirlenmesi ihtiyacı oluşmaktadır. Usulsüz kesimlerle orman alanından ağaçlar genellikle kolayca ve hızlı bir şekilde kesilebileceği bir yükseklikten kesilmekte ve kısa sürede ormandan çıkarılmaktadır. Çıkarılan emvalin hacmini belirlemek isteyen orman işletmesi yöneticileri, kesilen ağaçların gögüs yüksekliği çaplarını bilmedikleri için ağaç hacim tayininde güçlüklerle karşılaşmaktadırlar. Yukarıda da açıklandığı üzere, alanda kalan kütük yüksekliği genellikle 1,30 m’den daha kısa olduğundan, göğüs yüksekliği çapına bağlı olarak hazırlanmış olan hacım tablolarının kullanımı mümkün olmayacaktır. Bu nedenle, hacım tablolarının kullanılmasında gereken göğüs yüksekliği çapının alandaki dip kütüklerin çaplarından hesaplanması ihtiyacı hasıl olmaktadır. Bu amaçla Kalıpsız (1988)'tarafından, dip kütük çapı ile göğüs yüksekliğindeki çap arasındaki ilişkiden yararlanılması önerilmektedir.

Dip kütük çapı ile göğüs çapı arasındaki ilişkiyi belirlemek amacıyla gerek ülkemizde (Uğurlu ve Özer, 1977; Özer, 1981; Giray, 1982; Yavuz, 1996; Özçelik, 2005; Durkaya ve Durkaya, 2011; Sakıcı ve Yavuz, 2016; Sakıcı ve Özdemir, 2017; Şahin vd., 2019; Özdemir vd., 2020; Ercanlı vd.,2015; Sağlam vd., 2016), gerekse dünya da birçok araştırmacı tarafından (Demaerschalk ve Omule, 1982; Bylin, 1982a; Heiligmann vd., 1984; Wharton, 1984; Wiant ve Williams, 1987; Johnson ve Weigel, 1990; Corral-Rivas vd., 2007; Milios vd., 2016;) çeşitli çalışmalar yapılmıştır.

Yapılan çalışmaların çoğunluğunda kütük çapı olarak $0,30 \mathrm{~cm}$ yükseklik esas alınmıştır ve farklı kütük yükseklikleri hesaba katılmamıştır. Fakat Kalıpsız (1993) tarafından kütük yüksekliğinin hesaba katılmasının daha doğru sonuç vereceği belirtilmektedir. Bu çalışmada, hem farklı kütük yüksekliklerindeki çaplardan göğüs yüksekliği $\left(\mathrm{d}_{1,30}\right)$ çapına ulaşabilmek amacıyla uygun regresyon denklemleri denenmiş, ayrıca kütük çapı ve kütük yüksekliği birlikte kullanılarak göğüs yüksekliği çapına ulaşılmaya çalışılmıştır. Bu sayede özellikle usulsüz kesimlerle alandan uzaklaştırılan ağaçların göğ̈̈s çapları ve buna bağlı olarak ağaç hacimlerinin daha güvenilir bir şekilde belirlenmesi amaçlanmıştır. Bu amaç doğrultusunda Kastamonu Orman Bölge Müdürlüğü Bozkurt Orman İşletme Müdürlüğü, Göynük Orman İşletme Şefliği saf Kayın (Fagus orientalis Lipsky.) meşcerelerinde ölçümler yapılmıştır. Doğu kayını, asli ağaç türlerimiz içerisinde, 1.630.196 ha normal kapalı, 269.733 ha boşluklu kapalı olmak üzere 1.899.929 ha toplam yayılış alanı ile 4.sıradadır (URL 1). Kayın ormanlarımızın toplam serveti $263.772 .103 \mathrm{~m}^{3}$, yıllık toplam artım ise $6.130 .147 \mathrm{~m}^{3}$ 'tür (OGM, 2006). Saf meşcereler oluşturduğu gibi, Doğu ladini (Picea orientalis L.), Doğu Karadeniz Göknarı (Abies nordmanniana ssp. nordmanniana), Kazdağı Göknarı (A. nordmanniana ssp. equi-trojani ), Sarıçam (Pinus silvestris L.), Karaçam (Pinus nigra Arnold.) ve Meşe (Quercus sp.) ile karışımlar kurar. Doğu Akdeniz Bölgesinde Toros sediri (Cedrus libani A. Rich) ile lokal olarak ve çok dar bir alanda da Kızılçam (Pinus brutia Ten) ile karışık meşcerelerine rastlanmaktadır. Saf meşcerelerinde tek tabakalı bazen iki tabakalı kuruluşlarına da rastlanmaktadır. Bu çalışmada Göynük Orman İşletme Şefliği'de tohum kökenli saf kayın (Fagus orientalis Lipsky.) meşcerelerinde hem farklı kütük yüksekliklerinden $(0,10,0,30$ ve 0,60 m) ölçülen çaplardan, göğüs 
yüksekliği çapının $\left(\mathrm{d}_{1,30}\right)$ tahmini, hem de kütük çapları ve kütük yüksekliklerinden hareketle göğüs yüksekliğindeki çapın $\left(\mathrm{d}_{1,30}\right)$ tahmin edilmesi hedeflenmiştir.

\section{Materyal ve Metot}

Çalışmanın amacını gerçekleştirecek ölçümler, Kastamonu Orman Bölge Müdürlüğü, Bozkurt Orman İşletme Müdürlüğü, Göynük Orman İşletme şefliğinde yapılmıştır (Şekil 1). Örnek ağaçlar tohum kökenli saf kayın meşcerelerinden seçilmiştir. Örnek ağaçların, düzgün gövdeli, kusursuz ve sağlıklı olmalarına dikkat edilmiş ve alandaki çap basamaklarına dağıtılmasına özen gösterilmiştir. Çalışma alanından seçilen 200 adet örnek ağaç üzerinde 10, 30 ve 60 cm kütük yüksekliklerindeki kütük çevreleri ile $\mathrm{d}_{1,30}$ da ki gögüs yüksekliği çevresi ölçülmüştür. Çevre ölçümlerinden göğüs yüksekliği çap1 $\left(\mathrm{d}_{1,30}\right)$ ile ilgili kütük yüksekliklerindeki kütük çaplarına $\left(\mathrm{d}_{0,10}, \mathrm{~d}_{0,30}\right.$ ve $\left.\mathrm{d}_{0,60}\right)$ ulaşılmıştır. Örnek ağaçların çap dağılımları Şekil 2'de, ölçülen değerlere ilişkin bazı istatistiksel veriler Tablo 1'de verilmiştir.
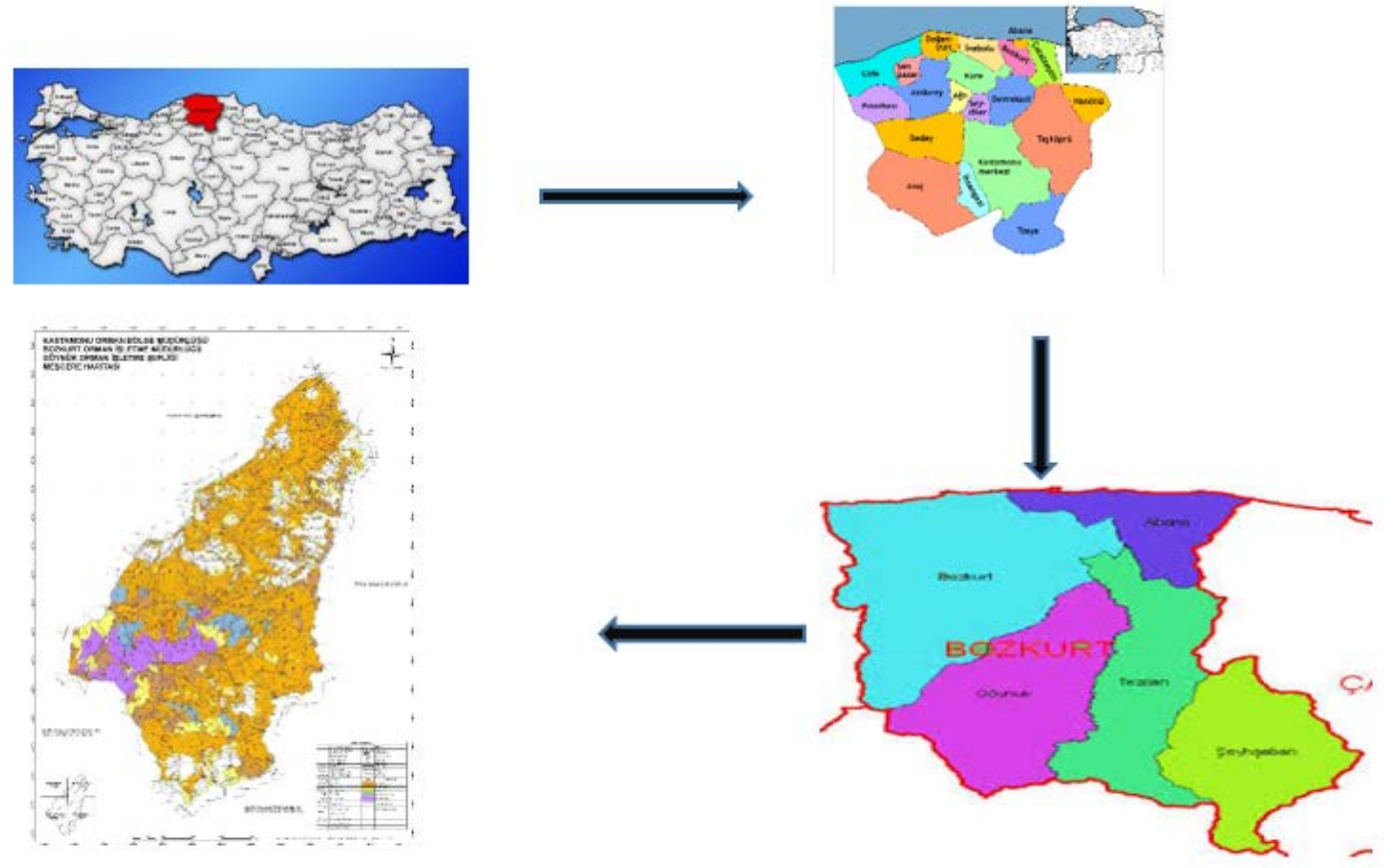

Şekil 1.Çalışma alanı.

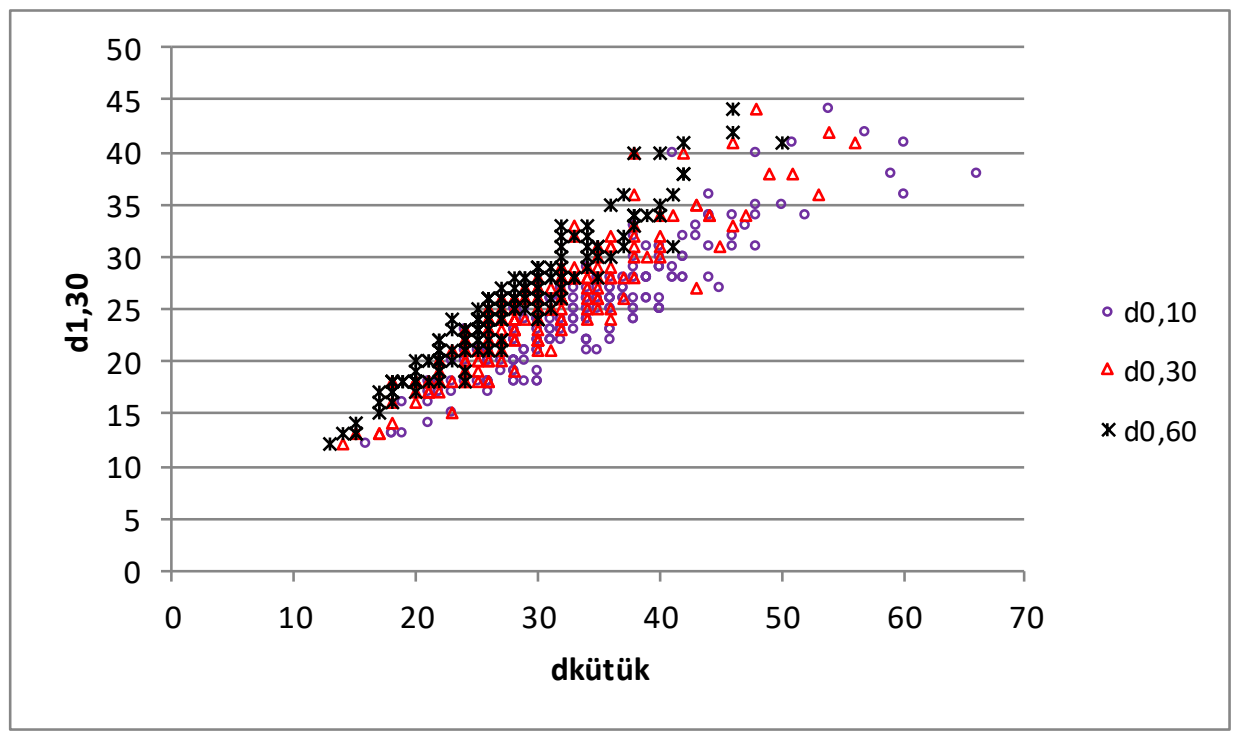

Şekil 2. Örnek ağaçların çap dağılımları 
Tablo1. Kayın örnek ağaçlarına ilişkin bazı istatistiksel veriler.

\begin{tabular}{lllllll}
\hline $\begin{array}{l}\text { Ağaç } \\
\text { Türü }\end{array}$ & Değişkenler & $\begin{array}{l}\text { Örnek sayısı } \\
\text { (n) }\end{array}$ & $\begin{array}{l}\text { Aritmetik } \\
\text { ortalama } \\
(\mathbf{c m})\end{array}$ & $\begin{array}{l}\text { Standart } \\
\text { Sapma } \\
(\mathbf{c m})\end{array}$ & $\begin{array}{l}\text { Min. } \\
(\mathbf{c m})\end{array}$ & $\begin{array}{l}\text { Max. } \\
(\mathbf{c m})\end{array}$ \\
\hline Kayın & $\mathrm{d}_{0,10}(\mathrm{~cm})$ & 200 & 34,1 & 8,4 & 16,6 & 66,6 \\
& $\mathrm{~d}_{0,30}(\mathrm{~cm})$ & 200 & 30,2 & 7,4 & 14,2 & 56,5 \\
& $\mathrm{~d}_{0,60}(\mathrm{~cm})$ & 200 & 27,3 & 6,5 & 13,9 & 50,2 \\
& $\mathrm{~d}_{1,30}(\mathrm{~cm})$ & 200 & 24,9 & 5,8 & 12,3 & 44,7 \\
\hline
\end{tabular}

Kayın ağaç türü için $0,10,0,30$ ve $0,60 \mathrm{~m}$ yüksekliklerindeki kütük çaplarının değerleri, göğüs çap1 değerleriyle ilişkiye getirilmek suretiyle tek girişli ilişkinin ortaya konulmasında, çeşitli kaynaklarda önerilmekte olan aşağıda verilen farklı regresyon (1-5 nolu) denklemleri denenmiştir.

$$
\begin{aligned}
& \mathrm{d}_{1,30}=\mathrm{a}_{0}+\mathrm{a}_{1} \mathrm{~d}_{\mathrm{k}} \\
& \mathrm{d}_{1,30}=\mathrm{a}_{0}+\mathrm{a}_{1} \mathrm{~d}_{\mathrm{k}}+\mathrm{a}_{2} \mathrm{~d}_{\mathrm{k}}{ }^{2} \\
& \mathrm{~d}_{1,30}=\mathrm{a}_{0}+\mathrm{a}_{1} \ln \left(\mathrm{d}_{\mathrm{k}}\right) \\
& \ln \left(\mathrm{d}_{1,30}\right)=\mathrm{a}_{0}+\mathrm{a}_{1} \ln \left(\mathrm{d}_{\mathrm{k}}\right) \\
& \mathrm{d}_{1,30}=\mathrm{a}_{0}+\mathrm{a}_{1} \mathrm{~d}_{\mathrm{k}}+\mathrm{a}_{2} \mathrm{~d}_{\mathrm{k}}{ }^{2}+\mathrm{a}_{3} \mathrm{~d}_{\mathrm{k}}{ }^{3}
\end{aligned}
$$

Ayrıca kütük çapı $\left(\mathrm{d}_{\mathrm{k}}\right)$ ve kütük yüksekliği $\left(\mathrm{h}_{\mathrm{k}}\right)$ ile göğüs yüksekliği çapı arasındaki çift girişli ilişkinin ortaya konulması amacıyla 8 farklı regresyon denklemi (6-13 nolu) denenmiştir.

$$
\begin{aligned}
& \mathrm{d}_{1,30}=\mathrm{a}_{0}+\mathrm{a}_{1} \mathrm{~d}_{\mathrm{k}}+\mathrm{a}_{2} \mathrm{~h}_{\mathrm{k}} \\
& \mathrm{d}_{1,30}=\mathrm{a}_{0}+\mathrm{a}_{1} \mathrm{~d}_{\mathrm{k}}+\mathrm{a}_{2} \mathrm{~d}_{\mathrm{k}} \mathrm{h}_{\mathrm{k}}+\mathrm{a}_{3} \mathrm{~h}_{\mathrm{k}} \\
& \mathrm{d}_{1,30}=\mathrm{a}_{0}+\mathrm{a}_{1} \mathrm{~d}_{\mathrm{k}} \mathrm{h}_{\mathrm{k}}+\mathrm{a}_{2} \mathrm{~d}_{\mathrm{k}}{ }^{2}+\mathrm{a}_{3} \mathrm{~h}_{\mathrm{k}}{ }^{2} \\
& \mathrm{~d}_{1,30}=\mathrm{a}_{0}+\mathrm{a}_{1} \mathrm{~d}_{\mathrm{k}}+\mathrm{a}_{2} \mathrm{~h}_{\mathrm{k}}+\mathrm{a}_{3} \mathrm{~d}_{\mathrm{k}}^{2}+\mathrm{a}_{4} \mathrm{~h}_{\mathrm{k}}^{2} \\
& \mathrm{~d}_{1,30}=\mathrm{a}_{0}+\mathrm{a}_{1} \mathrm{~d}_{\mathrm{k}}+\mathrm{a}_{2} \mathrm{~d}_{\mathrm{k}} \mathrm{h}_{\mathrm{k}}+\mathrm{a}_{3} \mathrm{~d}_{\mathrm{k}}{ }^{2}+\mathrm{a}_{4} \mathrm{~h}_{\mathrm{k}}+\mathrm{a}_{5} \mathrm{~d}_{\mathrm{k}}{ }^{2} \mathrm{~h}_{\mathrm{k}} \\
& \mathrm{d}_{1,30}=\mathrm{a}_{0}+\mathrm{a}_{1} \mathrm{~d}_{\mathrm{k}}+\mathrm{a}_{2} \mathrm{~d}_{\mathrm{k}} \mathrm{h}_{\mathrm{k}}+\mathrm{a}_{3} \mathrm{~d}_{\mathrm{k}}{ }^{2}+\mathrm{a}_{4} \mathrm{~d}_{\mathrm{k}}{ }^{2} \mathrm{~h}_{\mathrm{k}} \\
& \mathrm{d}_{1,30}=\mathrm{a}_{0}+\mathrm{a}_{1} \ln \left(\mathrm{d}_{\mathrm{k}}\right)+\mathrm{a}_{2} \ln \left(\mathrm{h}_{\mathrm{k}}\right) \\
& \ln \left(\mathrm{d}_{1,30}\right)=\mathrm{a}_{0}+\mathrm{a}_{1} \ln \left(\mathrm{d}_{\mathrm{k}}\right)+\mathrm{a}_{2} \ln \left(\mathrm{h}_{\mathrm{k}}\right) \\
& \mathrm{d}_{1,30}=\text { göğ̈̈s yüksekliği çap1,} \\
& \mathrm{d}_{\mathrm{k}}=\mathrm{kütük} \text { yüksekliğindeki çap1, } \\
& \mathrm{h}_{\mathrm{k}}=\mathrm{kütük} \text { yüksekliğini } \\
& \mathrm{a}_{0}, \mathrm{a}_{1}, \mathrm{a}_{2}, \mathrm{a}_{3}, \mathrm{a}_{4} \text { ve } \mathrm{a}_{5} \text { denklemin katsayılarını belirtmektedir }
\end{aligned}
$$

Denklemlerin uygunluğunu belirleyebilmek amacıyla; belirtme katsayısı (14) ve F değeri (16) en yüksek, standart hatası (15) en düşük olması istenen durumdur. Bunlara ilave olarak, denklemlerin Toplam Hata (\%) (17), Ortalama Mutlak Hata (\%) (18), Ortalama Sapma (19), Ortalama Mutlak Sapma (20) değerleri hesaplanarak, kullanılacak olan modelin, gerçek değerlere olan yakınlığına bakılmıştır (Kalıpsız, 1984; Reed ve Green, 1984; Durkaya vd. 2016). En uygun regresyon denkleminin belirlenmesinde kullanılan ölçütlerin bir ya da birkaçına göre güvenilir sonuçlar veren bir model, diğer ölçüt değerlerine göre tutarsız sonuçlar verebilmektedir. Bu nedenle Reed ve Green, (1984), tarafindan önerildiği şekliyle, modellerin değerlendirilmesinde tüm ölçüt değerlerini ihtiva eden bir başarı sıralaması tercih edilmiştir. Başarı sıralamasını; belirtme katsayısı ve F değeri en yüksek, standart sapma ve diğer ölçüt değerlerinin (TH (\%), $\mathrm{OMH}(\%)$, OS ve OMS) en düşük olduğu denkleme 1 değeri verilmiş ve artan sıra numarası ile diğer denklemlerde numaralandırılmıştır. Sonuç olarak denklemler arasından en uygun olan modelin seçiminde, her bir model için elde edilen toplam değerlerden, en düşük numaraya sahip olan denklem uygun model olarak seçilmiştir. Bu yöntem hem tek girişli modellerde hem de çift girişli modellerde aynı şekilde uygulanmıştır.

$$
R^{2}=1-\frac{\sum\left(y_{i}^{t}-y_{i}\right)^{2}}{\sum\left(y_{i}-y_{i}^{t}\right)^{2}}
$$




$$
\begin{aligned}
& S e=\sqrt{\frac{\left(y_{i}^{t} \cdot y_{i}\right)^{2}}{n-p}} \\
& F=\frac{S_{\text {reg }}^{2}}{S_{\text {hata }}^{2}} \\
& \text { TH(\%) }=\left[\frac{\left(\sum y_{i}^{t}-\sum y_{i}\right.}{\sum y_{i}}\right] \times 100 \\
& \text { OMH }(\%)=\left[\frac{\sum\left|y_{i}^{t}-y_{i}\right|}{\sum y_{i}}\right] \times 100 \\
& \text { OS }=\frac{1}{n} \sum\left(y_{i}^{t}-y_{i}\right) \\
& \text { OMS }=\frac{1}{n} \sum\left|y_{i}^{t}-y_{i}\right|
\end{aligned}
$$

Burada $y_{i}^{t}=$ göğüs çapının regresyon denkleminden elde edilen değeri, $y_{i}=$ göğüs çapı değeri $\mathrm{S}_{\text {reg; }}$; regresyon varyansını, $\mathrm{S}_{\text {hata; }}$ hata varyansını, $\mathrm{n}$; veri sayısını, $\mathrm{p}$; parametre sayısını, $\mathrm{y}_{\mathrm{i}}$; bağlı değiş̧kenin ölçülen değerini, $\mathrm{y}_{\mathrm{i}}^{\mathrm{t}}$; bağlı değişkenin regresyon modeli ile tahmin edilen değerlerini göstermektedir.

\section{Bulgular}

Göynük Orman İşletme Şefliği saf kayın meşcerelerinde kütük çapı $\left(\mathrm{d}_{\mathrm{k}}\right)$ ve göğüs yüksekliği çapı $\left(\mathrm{d}_{1,30}\right)$ ilişkisinin ortaya konulması amacıyla test edilmiş olan denklemler arasında ilişkileri en iyi yansıtan denklemin logaritmik model olan 4 nolu denklem olduğu görülmüştür (Şekil 3). Tablo 2'de $10 \mathrm{~cm}, 30 \mathrm{~cm}$ ve $60 \mathrm{~cm}$ kütük yüksekliklerindeki çap ile $d_{1,30}$ çapına ait uygun bulunan regresyon eşitliklerinin katsayı ve istatistikleri verilmiştir; Logaritmik olarak hesaplanan değerler \%1-2 oranında gerçek değerlerden küçük olmaktadır. Bu hatanın giderilmesi için, $f$ düzeltme faktörünün hesaplanması ve hesaplanan logaritmik değerlerin $\mathrm{f}$ faktörü ile çarpılarak hatanın düzeltilmesi gereklidir (Alemdağ, 1962). Bu amaçla hesaplanan denklemlerin f değerleri tabloda verilmektedir.

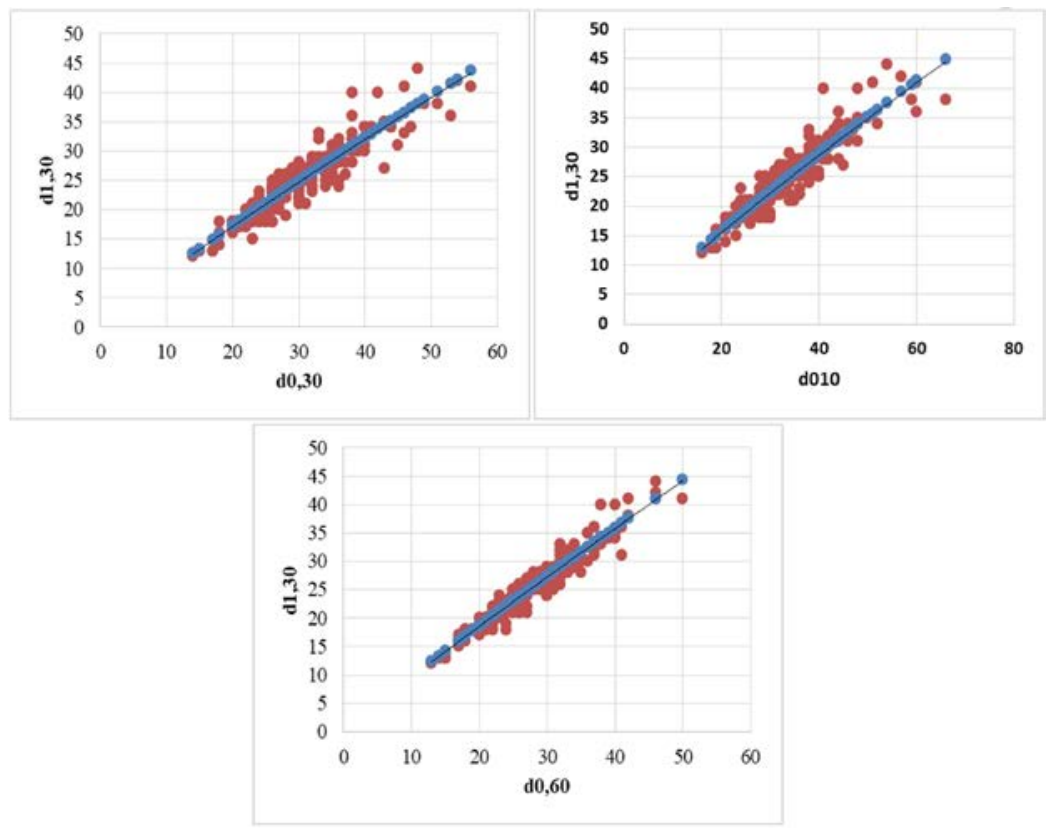

Şekil 3. Kütük çapı $\left(\mathrm{d}_{\mathrm{k}}\right)$ Göğüs çapı $\left(\mathrm{d}_{1,30}\right)$ ilişkisi. 
Tablo 2. Farklı yüksekliklerdeki göre kütük çap1- $\mathrm{d}_{1,30}$ çap1 arasındaki ilişkilere ait parametre ve istatistikler.

\begin{tabular}{|c|c|c|c|c|c|c|c|c|c|c|}
\hline $\begin{array}{l}\text { Kütük } \\
\text { Yüksekliği }\end{array}$ & $\begin{array}{l}\text { Regresyon } \\
\text { denklemi }\end{array}$ & $\overline{\mathbf{R}^{2}}$ & $\mathbf{F}$ & $\begin{array}{l}\mathrm{Se} \\
(\mathrm{cm})\end{array}$ & f & $\begin{array}{l}\text { TH } \\
(\%)\end{array}$ & $\begin{array}{l}\text { OMH } \\
(\%)\end{array}$ & OS & OMS & $\begin{array}{l}\text { Top } \\
\text {. }\end{array}$ \\
\hline \multirow[t]{5}{*}{$\mathrm{d}_{0,10}$} & $\begin{array}{l}\mathrm{d}_{1,30}=3,2999+0,632 \\
8 \mathrm{~d}_{0,1}\end{array}$ & $0,834(4)$ & $994(2)$ & $2,36(4)$ & - & $-0,004(2)$ & $7,15(2)$ & $-0,001(2)$ & $1,77(1)$ & 17 \\
\hline & $\begin{array}{l}\mathrm{d}_{1,30}=- \\
0,6086+0,8555 \mathrm{~d}_{0,1^{-}} \\
0,0030 \mathrm{~d}^{2}{ }_{01}\end{array}$ & $0,838(3)$ & $507(4)$ & 2,35(3) & - & $-0,053(3)$ & $7,11(1)$ & $-0,013(3)$ & $1,78(2)$ & 19 \\
\hline & $\begin{array}{l}\mathrm{d}_{1,30}=- \\
50,5793+21,5602 \mathrm{ln} \\
\mathrm{d}_{0,1}\end{array}$ & $0,821(5)$ & $913(3)$ & $2,45(5)$ & - & $-0,00028(1)$ & $7,49(3)$ & $0,00007(1)$ & $1,86(3)$ & 21 \\
\hline & $\begin{array}{l}\ln \left(d_{1,30}\right)=0,1028+0, \\
8813 \ln \left(d_{0,1}\right)\end{array}$ & $0,849(1)$ & $1117(1)$ & $0,09(1)$ & 1,009 & $0,503(4)$ & $7,15(2)$ & $0,12(4)$ & $1,77(1)$ & 14 \\
\hline & $\begin{array}{l}\mathrm{d}_{1,30}=10,8458- \\
0,1338 \mathrm{~d}_{0,1}+0,0238 \\
\mathrm{~d}^{2}, 1-0,0002 \mathrm{~d}^{3}, 1\end{array}$ & $0,841(2)$ & $345(5)$ & $2,33(2)$ & - & $5,19(5)$ & $8,85(4)$ & $1,29(5)$ & $2,20(4)$ & 27 \\
\hline \multirow[t]{5}{*}{$\mathrm{d}_{0,30}$} & $\begin{array}{l}\mathrm{d}_{1,30}=3,025+0,7224 \\
\mathrm{~d}_{0,3}\end{array}$ & $0,847(3)$ & $1095(2)$ & $2,27(3)$ & & $0,0015(2)$ & $6,84(4)$ & $0,0003(2)$ & $1,70(3)$ & 19 \\
\hline & $\begin{array}{l}\mathrm{d}_{1,30}=- \\
1,7137+1,0253 \mathrm{~d}_{0,3-} \\
0,0046 \mathrm{~d}^{2}{ }_{0,3}\end{array}$ & $0,851(2)$ & $564(3)$ & $2,47(5)$ & & $-0,141(4)$ & $6,70(2)$ & $-0,03(3)$ & $1,66(1)$ & 20 \\
\hline & $\begin{array}{l}d_{1,30}=- \\
49,8696+22,1096 l n \\
d_{0,3}\end{array}$ & $0,840(4)$ & 101(5) & $2,32(4)$ & & $-0,0003(1)$ & $6,95(5)$ & $-0,00008(1)$ & $1,73(4)$ & 24 \\
\hline & $\begin{array}{l}\ln \left(d_{1,30}\right)= \\
0,1402+0,9013\end{array}$ & $0,863(1)$ & $1124(1)$ & $0,08(1)$ & 1,008 & $0,46(5)$ & $6,63(1)$ & $0,115(4)$ & $1,69(2)$ & 15 \\
\hline & $\begin{array}{l}\mathrm{d}_{1,30}=0,0048- \\
0,8563 \mathrm{~d}_{0,3}+0,0006 \\
\mathrm{~d}^{2}{ }_{0,3}-0,00005 \mathrm{~d}^{3} 0,3\end{array}$ & $0,851(2)$ & $374(4)$ & $2,25(2)$ & & $-0,139(3)$ & $6,80(3)$ & $-0,03(3)$ & $1,73(4)$ & 21 \\
\hline \multirow[t]{5}{*}{$\mathrm{d}_{0,60}$} & $\begin{array}{l}\mathrm{d}_{1,30}=1,3620+0,862 \\
2 \mathrm{~d}_{0,6}\end{array}$ & $0,926(2)$ & $247(3)$ & $1,58(2)$ & & $-0,0004(1)$ & $4,73(4)$ & $-0,0001(1)$ & $1,17(3)$ & 16 \\
\hline & $\begin{array}{l}\mathrm{d}_{1,30}=0,3190+0,937 \\
5 \mathrm{~d}_{0} 6-0,0013 \mathrm{~d}^{2}, 6\end{array}$ & $0,926(2)$ & $120(5)$ & $1,58(2)$ & & $-0,042(3)$ & $4,70(1)$ & $-0,010(3)$ & $1,16(2)$ & 18 \\
\hline & $\begin{array}{l}\mathrm{d}_{1,30}=- \\
51,2291+23,2163 \ln \\
\mathrm{d}_{0,6}\end{array}$ & $0,903(3)$ & $180(4)$ & $1,80(4)$ & & $0,0006(2)$ & $5,30(5)$ & $0,0003(2)$ & $1,31(4)$ & 24 \\
\hline & $\begin{array}{l}\ln \left(d_{1,30}\right)= \\
0,0763+0,940 \\
\ln \left(d_{0,6}\right)\end{array}$ & $0,934(1)$ & $273(2)$ & $0,06(1)$ & 1,004 & $0,23(4)$ & $4,71(2)$ & $0,057(4)$ & $1,07(1)$ & 15 \\
\hline & $\begin{array}{l}\mathrm{d}_{1,30}=0,01455+0,95 \\
67 \mathrm{~d} 0,6+0,0019 \mathrm{~d}^{2}{ }_{0,3}^{-} \\
0,0000075 \mathrm{~d}^{3}{ }_{0,6}\end{array}$ & $0,926(2)$ & $816(1)$ & $1,59(3)$ & & $-0,35(5)$ & $4,72(3)$ & $-0,087(5)$ & $1,17(3)$ & 22 \\
\hline
\end{tabular}

Tüm kütük yükseklikleri düzeyinde denklemlerin başarı ölçütlerinin birbirine yakın değerler verdiği belirlenmiştir. Gögüs yüksekliğindeki $\left(\mathrm{d}_{1,30}\right)$ çapın, \%82-85 arasında $10 \mathrm{~cm}$ kütük yüksekliğindeki çapla; \%8486 arasında $30 \mathrm{~cm}$ kütük yüksekliğindeki çapla, \%90-93 arasında $60 \mathrm{~cm}$ kütük yüksekliğindeki çapla açıklanabildiği görülmüştür. Çalışma alanında ölçülen $\mathrm{d}_{1,30}$ göğüs çapı değerleri $12,3 \mathrm{~cm}$ ile $44,7 \mathrm{~cm}$ arasında değişmekte olup, $10 \mathrm{~cm}$ yüksekliğindeki kütük çapları ise 16,6-66,6 cm arasında değişmektedir. Bu nedenle çalışmada belirlenen regresyon denklemlerinin çok daha ileri gögüs çapları için hatalı sonuçlar verebileceği göz önüne alınarak ve ayrıca bağımlı değişkenin hesaplanabilmesi için, logaritmik hesaplama işlemi gerektiğinden dolayı kullanıcıya kolaylık olması amacıyla, 8-66 cm kütük çapları için 2'şer $\mathrm{cm}$ ara ile hesaplanan değerler Tablo 4'te verilmiştir.

Tablo 4. Kütük çapı değerlerine karşılık gelen göğüs yüksekliği çap değerleri.

\begin{tabular}{lllllllllll}
\hline Kayın & \multicolumn{1}{c}{ Kütük Çapları (cm) } \\
\cline { 2 - 11 } & $\mathbf{8}$ & $\mathbf{1 0}$ & $\mathbf{1 2}$ & $\mathbf{1 4}$ & $\mathbf{1 6}$ & $\mathbf{1 8}$ & $\mathbf{2 0}$ & $\mathbf{2 2}$ & $\mathbf{2 4}$ & $\mathbf{2 6}$ \\
\hline $\mathrm{d}_{0,10}-\mathrm{d}_{1,30}$ & 7 & 8,5 & 10,0 & 11,4 & 12,9 & 14,3 & 15,7 & 17,0 & 18,4 & 19,7 \\
$\mathrm{~d}_{0,30}-\mathrm{d}_{1,30}$ & 7,6 & 9,2 & 10,9 & 12,5 & 14,1 & 15,7 & 17,3 & 18,8 & 20,3 & 21,9 \\
$\mathrm{~d}_{0,60}-\mathrm{d}_{1,30}$ & 7,8 & 9,6 & 11,5 & 13,3 & 15,1 & 16,8 & 18,6 & 20,4 & 22,1 & 23,9 \\
& $\mathbf{2 8}$ & $\mathbf{3 0}$ & $\mathbf{3 2}$ & $\mathbf{3 4}$ & $\mathbf{3 6}$ & $\mathbf{3 8}$ & $\mathbf{4 0}$ & $\mathbf{4 2}$ & $\mathbf{4 4}$ & $\mathbf{4 6}$ \\
& 21,1 & 22,4 & 23,7 & 25,0 & 26,3 & 27,6 & 28,9 & 30,1 & 31,4 & 32,7 \\
$\mathrm{~d}_{0,10}-\mathrm{d}_{1,30}$ & 23,4 & 24,9 & 26,4 & 27,8 & 29,3 & 30,8 & 32,2 & 33,7 & 35,1 & 36,6 \\
$\mathrm{~d}_{0,30}-\mathrm{d}_{1,30}$ & 25,6 & 27,3 & 29,1 & 30,8 & 32,5 & 34,2 & 35,9 & 37,6 & 39,3 & 41,0 \\
$\mathrm{~d}_{0,60}-\mathrm{d}_{1,30}$ & $\mathbf{4 8}$ & $\mathbf{5 0}$ & $\mathbf{5 2}$ & $\mathbf{5 4}$ & $\mathbf{5 6}$ & $\mathbf{5 8}$ & $\mathbf{6 0}$ & $\mathbf{6 2}$ & $\mathbf{6 4}$ & $\mathbf{6 6}$ \\
& 38,0 & 39,4 & 36 & 37,6 & 38,8 & 40,1 & 41,3 & 42,5 & 43,7 & 44,9 \\
$\mathrm{~d}_{0,10}-\mathrm{d}_{1,30}$ & 38,0 & 39,4 & 40,8 & 42,2 & 43,7 & 45,1 & 46,5 & 47,8 & 49,2 & 50,6 \\
$\mathrm{~d}_{0,30}-\mathrm{d}_{1,30}$ & 42,7 & 44,4 & 46,1 & 47,7 & 49,4 & 51,1 & 52,8 & 54,4 & 56,1 & 57,8 \\
$\mathrm{~d}_{0,60}-\mathrm{d}_{1,30}$ & & & & & & & & & & \\
\hline
\end{tabular}

Çalışma alanına ait verilerle kayın dip kütük çapı $\left(d_{k}\right)$-kütük yüksekliği $\left(h_{k}\right)$ ile göğüs yüksekliği çapı $\left(d_{1,30}\right)$ arasındaki çift girişli ilişkinin ortaya konulması için denenmiş olan 8 farklı regresyon denklemine ait parametre ve istatistikleri Tablo 3'te verilmiştir. Çalışma sonucunda kayın için, 13 nolu çift girişli denklemin en uygun denklem olduğuna karar verilmiştir. 
Tablo 3. Kütük çapı- yüksekliği ile $\mathrm{d}_{1,30}$ çapı arasındaki ilişkilere ait parametre ve istatistikler.

\begin{tabular}{|c|c|c|c|c|c|c|c|c|c|}
\hline Regresyon denklemi & $\mathbf{R}^{2}$ & $\mathbf{F}$ & $\begin{array}{l}\text { Se } \\
(\mathrm{cm})\end{array}$ & $\mathbf{f}$ & $\begin{array}{l}\text { TH } \\
\text { (\%) }\end{array}$ & $\begin{array}{l}\text { OMH } \\
(\%)\end{array}$ & OS & OMS & Top. \\
\hline $\mathrm{d}_{1,30}=-0,1866+0,7163 \mathrm{~d}_{\mathrm{k}}+0,0956 \mathrm{~h}$ & $0,851(7)$ & $1704(3)$ & $2,23(7)$ & - & $-0,38(6)$ & $6,74(6)$ & $-0,09(6)$ & $1,67(6)$ & 41 \\
\hline $\mathrm{d}_{1,30}=-3,3201+0,6157 \mathrm{~d}_{\mathrm{k}}-0,003 \mathrm{~d}_{\mathrm{k}}-0,020 \mathrm{~h}_{\mathrm{k}}$ & $0,868(4)$ & $1313(4)$ & $2,10(4)$ & - & $0,16(3)$ & $6,35(3)$ & $-0,041(3)$ & $1,58(4)$ & 25 \\
\hline $\mathrm{d}_{1,30}=13,6843+0,0003 \mathrm{~d}_{\mathrm{k}} \mathrm{h}_{\mathrm{k}}+0,0098 \mathrm{~d}^{2}{ }_{\mathrm{k}}+0,0011 \mathrm{~h}^{2} \mathrm{k}$ & $0,772(8)$ & $675(8)$ & 2,76(8) & - & $-0,14(2)$ & $8,46(4)$ & $-0,035(2)$ & $2,10(7)$ & 39 \\
\hline $\mathrm{d}_{1,30}=-7,4469+1,0981 \mathrm{~d}_{\mathrm{k}}+0,1883 \mathrm{~h}_{\mathrm{k}}-0,0056 \mathrm{~d}^{2}{ }^{2}-0,0013 \mathrm{~h}^{2} \mathrm{k}$ & $0,865(5)$ & $951(6)$ & $2,13(5)$ & - & $-0,32(4)$ & $6,35(3)$ & $-0,08(5)$ & $1,58(4)$ & 32 \\
\hline $\begin{array}{l}\mathrm{d}_{1,30}=-1,2751+0,8606 \mathrm{~d}_{\mathrm{k}}+0,0035 \mathrm{~d}_{\mathrm{k}} \mathrm{h}_{\mathrm{k}}-0,0029 \mathrm{~d}^{2}{ }_{\mathrm{k}}+0,0021 \mathrm{~h}_{\mathrm{k}^{-}} \\
0,00002 \mathrm{~d}^{2} \mathrm{~h}_{\mathrm{k}}\end{array}$ & $0,873(2)$ & $818(7)$ & $2,07(2)$ & - & $0,35(5)$ & $6,35(3)$ & $0,08(5)$ & $1,57(3)$ & 27 \\
\hline $\mathrm{d}_{1,30}=-0,3986+0,8392 \mathrm{~d}_{\mathrm{k}}+0,0026 \mathrm{~d}_{\mathrm{k}} \mathrm{h}_{\mathrm{k}}-0,0035 \mathrm{~d}^{2} \mathrm{k}+0,00002 \mathrm{~d}^{2}{ }_{k} \mathrm{~h}_{\mathrm{k}}$ & $0,869(3)$ & 994(5) & 2,09(3) & & $-0,16(3)$ & $6,21(1)$ & $-0,041(3)$ & $1,54(1)$ & 19 \\
\hline$d_{1,30}=-59,3798+222567 \operatorname{lnd}_{k}+2,722 \operatorname{lnh}_{k}$ & $0,853(6)$ & $1738(2)$ & $2,22(6)$ & & $0,0006(1)$ & $6,60(5)$ & $0,0002(1)$ & $1,64(5)$ & 26 \\
\hline $\ln \left(d_{1,30}\right)=-0,2538+0,9089 \operatorname{lnd}_{k}+0,1111 \operatorname{lnh} h_{k}$ & $0,880(1)$ & 2198(1) & $0,08(1)$ & 1,007 & $0,35(5)$ & $6,28(2)$ & $0,067(4)$ & $1,56(2)$ & 16 \\
\hline
\end{tabular}

Uygun regresyon denklemi olarak seçilen 13 nolu logaritmik regresyon denklemi kullanılarak türetilen değerler tablo halinde düzenlenmiştir. 5-100 cm'lik kütük yükseklikleri ve bu yüksekliklerdeki çaplara karşılık 5-65 cm gelen kütük çapı değerleri, f düzeltme faktörü ile düzeltilmiş olarak, Tablo 5'de verilmiştir.

Tablo 5. Kayın için, kütük çapı-kütük yüksekliğine bağlı olarak $\mathrm{d}_{1,30}$ çapı tablosu.

\begin{tabular}{|c|c|c|c|c|c|c|c|c|c|c|c|c|c|}
\hline \multirow{2}{*}{$\begin{array}{l}\text { KAYIN } \\
\text { Kütük } \\
\text { yüksekliği } \\
\text { (cm) }\end{array}$} & \multicolumn{13}{|c|}{ Kütük Çapları(cm) } \\
\hline & 5 & 10 & 15 & 20 & 25 & 30 & 35 & 40 & 45 & 50 & 55 & 60 & 65 \\
\hline 5 & 4,0 & 7,6 & 10,9 & 14,2 & 17,4 & 20,6 & 23,7 & 26,7 & 29,7 & 32,7 & 35,7 & 38,6 & 41,5 \\
\hline 10 & 4,4 & 8,2 & 11,8 & 15,4 & 18,8 & 22,2 & 25,6 & 28,8 & 32,1 & 35,3 & 38,5 & 41,7 & 44,8 \\
\hline 15 & 4,6 & 8,6 & 12,4 & 16,1 & 19,7 & 23,2 & 26,7 & 30,2 & 33,6 & 37,0 & 40,3 & 43,6 & 46,9 \\
\hline 20 & 4,7 & 8,8 & 12,8 & 16,6 & 20,3 & 24,0 & 27,6 & 31,2 & 34,7 & 38,2 & 41,6 & 45,0 & 48,4 \\
\hline 25 & 4,8 & 9,1 & 13,1 & 17,0 & 20,8 & 24,6 & 28,3 & 31,9 & 35,5 & 39,1 & 42,7 & 46,2 & 49,6 \\
\hline 30 & 4,9 & 9,2 & 13,4 & 17,4 & 21,3 & 25,1 & 28,9 & 32,6 & 36,3 & 39,9 & 43,5 & 47,1 & 50,7 \\
\hline 35 & 5,0 & 9,4 & 13,6 & 17,7 & 21,6 & 25,5 & 29,4 & 33,2 & 36,9 & 40,6 & 44,3 & 47,9 & 51,5 \\
\hline 40 & 5,1 & 9,5 & 13,8 & 17,9 & 21,9 & 25,9 & 29,8 & 33,6 & 37,5 & 41,2 & 44,9 & 48,6 & 52,3 \\
\hline 45 & 5,2 & 9,7 & 13,9 & 18,2 & 22,2 & 26,2 & 30,2 & 34,1 & 37,9 & 41,8 & 45,5 & 49,3 & 53,0 \\
\hline 50 & 5,2 & 9,8 & 14,1 & 18,4 & 22,5 & 26,6 & 30,6 & 34,5 & 38,4 & 42,2 & 46,1 & 49,9 & 53,6 \\
\hline 55 & 5,3 & 9,9 & 14,3 & 18,6 & 22,7 & 26,8 & 30,9 & 34,9 & 38,8 & 42,7 & 46,6 & 50,4 & 54,2 \\
\hline 60 & 5,3 & 9,9 & 14,4 & 18,7 & 22,9 & 27,1 & 31,2 & 35,2 & 39,2 & 43,1 & 47,0 & 50,9 & 54,7 \\
\hline 65 & 5,4 & 10,1 & 14,6 & 18,9 & 23,2 & 27,3 & 31,5 & 35,5 & 39,5 & 43,5 & 47,4 & 51,3 & 55,2 \\
\hline 70 & 5,4 & 10,2 & 14,7 & 19,1 & 23,4 & 27,6 & 31,7 & 35,8 & 39,9 & 43,9 & 47,8 & 51,8 & 55,7 \\
\hline 75 & 5,5 & 10,2 & 14,8 & 19,2 & 23,5 & 27,8 & 32,0 & 36,1 & 40,2 & 44,2 & 48,2 & 52,2 & 56,1 \\
\hline 80 & 5,5 & 10,3 & 14,9 & 19,4 & 23,7 & 28,0 & 32,2 & 36,3 & 40,4 & 44,5 & 48,5 & 52,5 & 56,5 \\
\hline 85 & 5,5 & 10,4 & 15,0 & 19,5 & 23,7 & 28,2 & 32,4 & 36,6 & 40,7 & 44,8 & 48,9 & 52,9 & 56,9 \\
\hline 90 & 5,6 & 10,4 & 15,1 & 19,6 & 24,0 & 28,4 & 32,6 & 36,8 & 41,0 & 45,1 & 49,2 & 53,2 & 57,2 \\
\hline 95 & 5,6 & 10,5 & 15,2 & 19,7 & 24,2 & 28,5 & 32,8 & 37,0 & 41,2 & 45,4 & 49,5 & 53,5 & 57,6 \\
\hline 100 & 5,6 & 10,6 & 15,3 & 19,8 & 24,3 & 28,7 & 33,0 & 37,3 & 41,5 & 45,6 & 49,8 & 53,9 & 57,9 \\
\hline
\end{tabular}

\section{Sonuç ve Tartışma}

Ormancılık pratiğinde arazide usulsüz yapılan kesimlerdeki kütük çaplarının 0,8 katsayısı ile çarpılarak göğüs yüksekliğindeki çapa ulaşılması tavsiye edilmektedir (Giray, 1982). Ancak her kütük yüksekliğinde ve her ağaç türünde bu katsayıyı kullanmak çeşitli maddi hatalara sebep olabilecektir. Çalışma sonucunda Tablo 4 ve Tablo 5'deki değerler kullanılarak çalışma alanında gögüus yüksekliğindeki çaplar elde edilebilecektir. Bununla birlikte uygulamada daha pratik kullanım sağlamak amacıyla çalışmada denenmiş olan 1 nolu denklem, ki bu denklem seçilen 4 nolu denklemden sonra en iyi başarı sırası değerine sahiptir, sabit katsayısı denklemden çıkarılarak yeniden hesaplanmıştır. Sabit terimin çıkarılmasıyla hesaplanan regresyon denklem ve istatistikleri daha pratik kullanım için Tablo 6'da verilmiştir. 
Tablo 6. Sabit terimin çıkarılarak hesaplanan 1 nolu denklem ve katsayıları.

\begin{tabular}{lllllllll}
\hline $\begin{array}{l}\text { Kütük } \\
\text { Yüksekliği } \\
(\mathbf{c m})\end{array}$ & $\begin{array}{l}\text { Regresyon } \\
\text { denklemi }\end{array}$ & $\mathbf{R}^{2}$ & $\mathbf{F}$ & $\begin{array}{l}\text { Se } \\
(\mathbf{c m})\end{array}$ & $\begin{array}{l}\text { TH } \\
\mathbf{( \% )}\end{array}$ & $\begin{array}{l}\text { OMH } \\
\mathbf{( \% )}\end{array}$ & OS & OMS \\
\hline 10 & & & & & & & $-0,18$ & 1,86 \\
30 & $\mathrm{~d}_{1,30}=0,72 \mathrm{~d}_{0,1}$ & 0,990 & 20812 & 2,49 & $-0,74$ & 7,48 & $-0,16$ & 1,81 \\
60 & $\mathrm{~d}_{1,30}=0,82 \mathrm{~d}_{0,3}$ & 0,991 & 22813 & 2,38 & $-0,63$ & 7,27 & $-0,13$ \\
\hline
\end{tabular}

Denklemlerin uygunluğunun kontrolü için hesaplanan toplam mutlak hata yüzdeleri denklemlerin rahatlıkla kullanılabileceğini göstermektedir. Tablo 6'dan görüleceği üzere, $10 \mathrm{~cm}$ kütük yüksekliği için; $\mathrm{d}_{1,30}=0,72 \mathrm{~d}_{0,10}$ denklemi, $30 \mathrm{~cm}$ kütük yüksekliği için $\mathrm{d}_{1,30}=0,82 \mathrm{~d}_{0,30}, 60 \mathrm{~cm}$ kütük yüksekliği için $\mathrm{d}_{1,30}=0,91 \mathrm{~d}_{0,60}$ denklemlerine ulaşılmıştır. Bu katsayılar doğrudan çarpan olarak kullanılabilir. Benzer çalışmalarda da benzer sonuçların ortaya koyulduğu görülmektedir (Sakıc1-Yavuz, 2016, Şahin vd., 2019). Denklem katsayılarının artan kütük yüksekliğine bağlı olarak arttığı tespit edilmiştir. Bu artışın Durkaya ve Durkaya (2011) tarafindan Zonguldak-Ulus İşletmesi Kayın için yapılan çalışmaya benzer olduğu görülmüştür. Bu çalışmayla kıyaslama yapıldığında katsayıların farklılıkları dikkat çekmektedir; Durkaya ve Durkaya (2011)’de $10 \mathrm{~cm}$ kütük yüksekliğinde 0,$832 ; 30 \mathrm{~cm}$ kütük yüksekliğinde 0,$892 ; 60 \mathrm{~cm}$ kütük yüksekliğinde 0,948 olarak hesaplanmıştır. Buna göre aynı ağaç türü dahi olsa yetişme ortamı koşullarına bağlı olarak göğüs çapının hesaplanmasında yöresel katsayıların kullanılması daha doğru sonuçlar verecektir.

Çalışma sonucunda Kastamonu Orman Bölge Müdürlüğü Bozkurt Orman İşletme Müdürlüğü, Göynük Orman İşletme Şefliğinde yayılış gösteren saf kayın (Fagus orientalis Lipsky.) ağaç türü için farklı kütük yüksekliklerinden ölçülen çap1 ve kütük çap1-kütük yüksekliği değerlerine bağlı olarak göğüs yüksekliği çapının $\left(\mathrm{d}_{1,30}\right)$ tahmininin belirlenen denklemler kullanılarak hesaplanabileceği sonucuna varılmıştır. Çalışmadan elde edilen sonuçlar, meşcerelerden usulsüz şekilde uzaklaştırılan ağaçların gögüs çaplarının tahmininde güvenle kullanılabilir. Gögüs çapı tahmin edilen ağaçların hacim değerleri hacım tabloları yardımıyla belirlenebilecektir. Çalışmaya konu edilen ağaçların gögüs çapı değerleri $12,3 \mathrm{~cm}$ ile $44,7 \mathrm{~cm}$ arasında değişmektedir. Bu çap aralığı için çalışma sonuçlarının daha güvenilir olacağı muhakkaktır, çalışma sonuçlarının çok daha ileri göğüs çapları için hatalı sonuçlar verebileceği göz önüne alınarak kullanılması önerilebilir. Yukarıdaki açıklamalardan görüleceği üzere, iki farlı yetişme ortamında kayın türü için farklı sonuçlara ulaşılmıştır. Bu sebeple, bu tür çalışmaların farklı yetişme ortamları için çeşitlendirilmesi önerilebilir.

\section{Kaynaklar}

1. Alemdă̆ İ. Ş. (1962). Türkiye'deki Kızılçam Ormanlarının Gelişimi Hassılatı ve Amenajman Esasları Üzerine Araştırmalar. Ormancılık Araştırma Enstitüsü Teknik Bülten No:11, 160s.

2. Bylin, C. V. (1982). Estimating dbh from stump diameter for 15 southern species. Res. Note 50-286. New Orleans, LA: U.S. Department of Agriculture, Forest Service, Southern Forest Experiment Station:3

3. Corral-Rivas, J.J., Barrio-Anta, M., Aguirre-Calderón, O. A., Diéguez-Aranda, U., (2007). Use of stump diameter to estimate diameter at breast height and tree volume for major pine species in El Salto, Durango (Mexico). Forestry, 80(1), 29-40.

4. Demaerschalk J.P., Omule, S. A. Y. (1982). Estimating Breast Height Diameter from Stump Measurements in British Columbia, Forest Chronicle, 58(3), 143-145.

5. Durkaya A, Durkaya, B., Ulu Say, Ş. (2016). Below-and above ground biomass distribution of young Scots pines from plantations and natural stands. Bosque 37(3), 509-518, 2016 DOI: 10.4067/S071792002016000300008.

6. Durkaya, A., Durkaya, B., Ünsal, A. (2009). Predicting the above-ground biomass of calabrian pine (Pinus brutia Ten.) stands in Turkey. African Journal of Biotechnology Vol 8(11), pp. 2483-2488 ISSN 1684-5315 (C) 2009 Academic Journals.

7. Durkaya, B., Durkaya, A. (2011). Zonguldak-Ulus Orman İşletme Müdürlüğü göknar, kayın ve karaçam ağaç türleri için kütük çapı ve boyu ile göğüs çapı ilişkisi. Kastamonu Üniversitesi Orman Fakültesi Dergisi, 11(1): 9-17.

8. Durkaya, B., Durkaya, A., Yagcı, H. (2019). Biomass equations in natural black pines. Fresenius Environmental Bulletin. 28(2A/2019), 1132-1139.

9. Ercanl, İ., Günlü, A., Başkent, E.Z. (2015). Mixed effect models for predicting breast height diameter from stump diameter of Oriental beech in Göldağ. Scientia Agricola, 72(3), 245-251. 
10. Giray, N. (1982). Ağaçlarda kütük çapı, orta çap, göğüs çapı ilişkisi. Ormancılık Araştırma Enstitüsü Dergisi, 28, 69-79. (in Turkish)

11. Heiligmann, R., Golitz, M., Dale, M. (1984). Predicting board-foot tree volume from stump diameter for eight Hardwood Species in Ohı. The Ohio Academy of Science, 84(5), 259-263,

12. Johnson, D. S., Weigel, D. R. (1990). Models for Estimating DBH from Stump Diameter for Southern Indiana Oaks, Northern Journal of Applied Forestry. 7(2), 79-81.

13. Kalıpsız, A. (1993). Dendrometri. İÜ Yayın No:3793, Fakülte Yayın No:426, ISBN 975-404-358-2, 407s. İstanbul.

14. Milios, E., Kitikidou, K. G., Dalakouras, V., Pipinis, E. (2016). Diameter at breast height estimated from stumps in Quercus frainetto in the region of Evros in Northeastern Greece. Cerne, 22(3): 337-344.

15. OGM (2015). Orman Varlığımız. http://web.ogm.gov.tr/ekutuphane/Yayinlar / https://web.ogm.gov.tr/ekutuphane/Yayinlar/T\%C3\%BCrkiye\%20Orman\%20Varl\%C4\%B1\%C4\%9F\%C 4\%B1-2016-2017.pdf

16. Özçelik, R., Brooks, J. R., Diamantopoulou, M. J., Wiant Jr, H. V. (2010). Estimating breast height diameter and volume from stump diameter for three economically important species in Turkey. Scandinavian Journal of Forest Research, 25(1), 32-45.

17. Özçelik, R. (2005). Mut Orman İşletmesinde Karaçam, Sedir ve Kızılçam Ağaç Türleri İçin Dip ÇapGöğüs Çapı İlişkileri. SDÜ Fen Bilimleri Enstitüsü Dergisi, 9-3, 83-91.

18. Özdemir, E., Şahin, A., Özdemir, G. A. (2020). Kuzey Marmara Yöresi sapsız meşe (Quercus petraea (Matt.) Liebl) meşcereleri için kütük çapı-göğüs çapı ilişkisinin belirlenmesi. Türkiye Ormancılık Dergisi, 21(1), 25-34.

19. Özer, E. (1981). Sarıçamlarda kütük çapından yararlanarak göğüs çapının bulunması. Ormancıllk Araştırma Enstitüsü Dergisi, 53(27), 20-23.

20. Reed, D. D., Green, E. J. (1984). Compatible stem taper and volume ratio equations. Forest Science, 30(4), 977-990.

21. Sağlam, F., Sakıcı, O.E., Seki, M. (2016). The relationships between stump diameter and diameter at breast height for Chestnut (Castanea sativa Mill.) stands in Kastamonu coastal region, International Forestry Symposium, (7-10 December 2016), 514-520, Kastamonu, Turkey.

22. Sakıcı, O. E., Yavuz, H. (2016). The relationship between diameter at stump height and diameter at breast height in Red pine-Black pine mixed stands. In Scientific Research Symposium in Turkish World (pp. 29-31).

23. Sakıcı, O.E., Özdemir, G. (2017). Stump diameter and diameter at breast height relationships for oriental beech and Kazdağı fir at mixed stands in Karabük. Kastamonu Üniversitesi Orman Fakültesi Dergisi, 17(2), 298-306.

24. Şahin, A., Kahriman, A., Göktürk, A. (2019). Estimating diameter at breast height (DBH) from diameter at stump height (DST) in triple mixed stands in the region of Artvin in Turkey. Forestist, 69(1), 61-67.

25. Uğurlu, S., Özer, E. (1977). Kızılçamlarda kütük çapından yararlanarak göğüs çapının hesaplanması. Ormancılık Araştırma Enstitüsü Dergisi, 23(1), 71-77.

26. Wharton, E. H. (1984). Predicting diameter at breast height from stump diameters for Northeastern tree species. USDA Forest Service Research Note NE-322, Northeastern Forest Experiment Station.

27. Wiant, H. U. Jr., Williams, T. B. (1987). Lower Bole Diameter and Wolume of Appalachian Hardwoods, Northern Journal of Applied Forestry, 4(212).

28. Yavuz, H. (1996). Taşköprü Orman İşletmesinde Sarıçam ve Karaçam Ağaç Türlerimize İlişkin Dip ÇapGögüs Çapı-Orta Çap İlişkileri ile Kabuk Hacminin Hesaplanması. KTÜ Orman Fakültesi Bahar Seminerleri, Seminer No: 2, 67-75.

29. Yavuz, H. (2000). Dişbudak Ağaç Türü için Dip Kütük Çapı ile Göğüs Çapı Arasındaki İlişkinin Belirlenmesi, KTÜ Orman Fakültesi Güz Seminerleri, Seminer No:7. 